\title{
Avaliação da qualidade do ar em um polo produtor de ferro-gusa
}

\author{
Evaluation of the air quality in a pig iron production pole
}

\author{
Vanusa Maria Feliciano Jacomino \\ Física. Doutora em Tecnologia Nuclear pelo Instituto de Física da Universidade de São Paulo (USP). Pesquisadora do Centro de Desenvolvimento da \\ Tecnologia Nuclear/Comissão Nacional de Energia Nuclear (CDTN/CNEN)
}

\begin{abstract}
Alberto Avellar Barreto
Engenheiro mecânico. Doutor em Engenharia Mecânica pela Universidade Federal de Minas Gerais (UFMG). Pesquisador do CDTN/CNEN
\end{abstract}

Fernanda Vasconcelos Fonseca Tavares

Física. Mestre em Ciência e Tecnologia das Radiações, Minerais e Materiais pelo CNEN/CDTN

Claudia Marques Peixoto

Graduanda em Gestão Ambiental pela Universidade do Sul de Santa Catarina (Unisul). Técnica em instrumentação do CDTN/CNEN

Paulo César Horta Rodrigues

Geólogo. Doutor em Cristaloquímica pela Johannes Gutenberg Univesität, Alemanha. Pesquisador do CDTN/CNEN

\section{Resumo}

Este estudo se iniciou com a realização de um inventário das fontes de emissão de material particulado existentes no município de Sete Lagoas (MG). Com base nessas informações e nos parâmetros meteorológicos e topográficos da região, foi feita a seleção dos pontos de maior concentração de material particulado inalável $\left(\mathrm{MP}_{10}\right)$ usando o modelo ISC3. Um dos pontos identificados se situa na área central do município. Nesse local foram coletadas várias amostras de material particulado (MP) para determinação das composições mineralógica e elementar das partículas de aerossol $\left(\mathrm{MP}_{10}\right)$. A calcita foi o mineral mais abundante $(>30 \%)$ e o $\mathrm{Na}$, Ba e o Fe foram os elementos-traço presentes em maior proporção no material coletado. A análise de fatores principais mostrou que a ressuspensão de poeira de solo e as atividades industriais são os maiores contribuintes de emissão do MP naquela área.

Palavras-chave: qualidade do ar; material particulado; modelo receptor.

\section{Abstract}

This study started with the inventory of the main particulate emission sources of Sete Lagoas city, Minas Gerais, Brazil. Based on this data and on local meteorological and topographic parameters, the selection of the highest points of inhalable particulate $\left(\mathrm{PM}_{10}\right)$ concentrations was carried out using the ISC3 model. One of the identified points is situated on the central area of the city. Several samples of particulate matter (PM) were collected in that site for the determination of the mineralogical and elemental composition of the aerosol particles ( $\left.\mathrm{PM}_{10}\right)$. Calcite was the most abundant mineral (> 30\%), and $\mathrm{Na}$, $\mathrm{Ba}$ and Fe were the trace elements presented in larger proportion in the collected material. The analysis of the main factors showed that resuspension of soil dust and industrial sources were the largest contributors of PM emissions in that area.

Keywords: air quality; particulate matter; receptor model. 


\section{Introdução}

A questão da poluição atmosférica vem se agravando nos últimos anos devido principalmente à expansão populacional e industrial. Esse problema atinge não apenas os grandes aglomerados urbanos e industriais, mas também centros urbanos menores. A degradação da qualidade do ar pode causar sérios problemas à condição de vida das pessoas e ecossistemas.

Consequentemente, a medição da concentração de poluentes presentes na atmosfera é fundamental, uma vez que os seus resultados permitem não apenas o acompanhamento sistemático da qualidade do ar na área monitorada, mas também a elaboração de diagnósticos, que podem auxiliar o governo em ações direcionadas ao controle das emissões.

A utilização de técnicas experimentais baseadas, principalmente, em redes de monitoramento, possibilita o conhecimento das condições da qualidade do ar somente nas regiões onde os dados são coletados (CETESB, 2007). Os equipamentos de investigação da concentração de poluentes são caros e necessitam de uma estrutura para o acompanhamento contínuo das condições de operação, de forma a garantir a qualidade da informação obtida.

Simulações numéricas são ferramentas amplamente utilizadas para avaliar os mecanismos de dispersão de poluentes na atmosfera. Elas fornecem uma estimativa teórica dos níveis de poluentes no ar, bem como informações espaciais e temporais sobre a evolução desses poluentes na atmosfera (GODISH, 2007). As simulações numéricas também são utilizadas para representar cenários futuros, o que possibilita a antecipação de medidas de controle.

Para expandir o conhecimento sobre a qualidade do ar, frequentemente são utilizadas técnicas experimentais em combinação com recursos de simulação. Teoricamente, a avaliação da contribuição de fontes poluidoras da atmosfera pode ser feita usando-se dois tipos de modelos matemáticos: o fonte e o receptor (GODISH, 1997; QUEIROZ, 2006).

O modelo fonte parte do princípio de que os dados referentes às taxas de emissão de fontes específicas e as condições de dispersão são conhecidos. A partir dessas informações, pode-se calcular a contribuição das fontes emissoras no sítio receptor. Existem numerosos modelos matemáticos que descrevem os fenômenos de transporte e difusão de poluentes na atmosfera, sendo o modelo gaussiano (USEPA, 1995) um dos mais usados.

O modelo receptor se baseia em propriedades do aerossol que são comuns à fonte e ao receptor. As principais características estudadas são a composição química e o tamanho das partículas. O principal argumento a favor desse modelo é o princípio de conservação de massa (HOPKE, 2003). No atual estágio de desenvolvimento, os modelos receptores têm se mostrado mais apropriados à aplicação de estratégias de controle sobre condições já estabelecidas, pois podem fornecer a parcela de responsabilidade das principais fontes a partir de amostragens de controle da qualidade do ar.
$\mathrm{Na}$ prática, a aplicação desses modelos envolve o tratamento estatístico de dados de concentração de elementos-traço presentes no material particulado e de informações meteorológicas, sendo geralmente utilizados métodos de análise estatística multivariada que consideram a correlação entre muitas variáveis analisadas ao mesmo tempo (HOPKE, 2003).

No Brasil, esses modelos têm sido aplicados em especial no Estado de São Paulo, para avaliar os perfis de fontes de emissão de poluentes atmosféricos em municípios considerados de grande e médio porte. Bruno (2006), por exemplo, utilizou modelos receptores por meio da aplicação da análise de fatores principais (AFP) e do modelo de balanço químico de massas (BQM) para quantificar as prováveis fontes poluidoras responsáveis pela carga de material particulado (MP) no município de São Carlos (SP). Em Araraquara (SP), foram identificadas como maiores fontes do aerossol: tráfego de veículos, emissões industriais e componentes típicos de queimadas, como $\mathrm{K}$ e Cl (CETESB, 2000). Estudos realizados por Kerr e Orsini (1996), com o uso da técnica do modelo receptor em Vila Parisi, Cubatão (SP), mostraram ser decisiva a participação do grupo de indústrias de fertilizantes na formação do material particulado suspenso na atmosfera local.

O aerossol atmosférico de São Paulo tem sido estudado continuamente desde 1983, podendo ser citados, por exemplo, os trabalhos realizados por Andrade et al (1993), Castanho e Artaxo (2001), Miranda et al (2002), Orsini et al (1986). Existe uma concordância entre as análises aplicadas por esses autores no que se refere à identificação dos padrões de fontes características de São Paulo: apesar do grande número de indústrias presentes na região, as maiores contribuições para as elevadas concentrações de material particulado são provenientes, principalmente, da ressuspensão do solo e das emissões veiculares.

O município de Sete Lagoas, localizado no centro-oeste de Minas Gerais, concentra um grande número de pequenas e médias indústrias, em especial as usinas de produção de ferro-gusa a carvão vegetal. Relatórios estatísticos (QUEIROZ, 2006), gerados a partir dos resultados de monitoramento da qualidade do ar nesse município, confirmam que em alguns dos pontos de amostragem os níveis de material particulado na atmosfera são elevados e que, dependendo da época do ano, ultrapassam os limites estabelecidos pelo Conselho Nacional de Meio Ambiente (BRASIL, 1990). Esse material é emitido para a atmosfera em decorrência, principalmente, das operações de estocagem, manuseio e transporte de matérias-primas, bem como da queima de combustíveis utilizados nas várias etapas do processo produtivo.

O principal objetivo deste trabalho foi aplicar um conjunto de metodologias experimentais e computacionais para identificar a contribuição das principais fontes de emissão de material particulado inalável $\left(\mathrm{MP}_{10}\right)$ na composição do aerossol atmosférico presente na região de Sete Lagoas. Os resultados obtidos contribuíram para o 
entendimento dos mecanismos de dispersão dos poluentes atmosféricos (em especial o material particulado). As informações obtidas estão à disposição dos empreendedores e instituições ambientais para auxiliar na tomada de uma série de ações que levem à melhoria da qualidade ambiental, tais como: otimização da rede de monitoramento da qualidade do ar, avaliação dos impactos ao meio ambiente e realização de previsões quanto aos impactos gerados com a entrada em operação de novos processos.

\section{Metodologia}

\section{Aplicação do modelo fonte}

A estimativa das concentrações de material particulado na área de interesse em decorrência da emissão de material particulado por fontes fixas e móveis foi realizada utilizando o ISC3 (Industrial Source Complex Model) (USEPA, 1995). Conhecido como "modelo da pluma gaussiana", vem sendo utilizado há mais de duas décadas por órgãos ambientais para a realização de estudos de dispersão atmosférica. Tal modelo utiliza dados meteorológicos horários (temperatura do ar, velocidade e direção do vento, estabilidade atmosférica e altura da camada de mistura) e dados da fonte de emissão de poluentes (localização e altura da fonte, taxa de emissão, temperatura e velocidade de saída dos gases)

O modelo foi aplicado em uma área de $33 \mathrm{~km}$ (leste-oeste) por $25 \mathrm{~km}$ (norte-sul). A topografia desse local é caracterizada por uma grande diversidade de altitudes, sendo a altitude média do terreno igual a $788 \mathrm{~m}$, a cota mínima de $640 \mathrm{~m}$, e a máxima, de $1.075 \mathrm{~m}$. Esse tipo de terreno, associado às posições das fontes, é caracterizado no modelo como "complexo".

O levantamento de informações das fontes emissoras foi realizado tanto in loco (visitas técnicas), quanto em investigações nos processos de licenciamento existentes no órgão ambiental. Dos 114 empreendimentos identificados, apenas 23 possuíam fontes cuja taxa de emissão de material particulado para a atmosfera pudesse ser considerada significativa. As visitas técnicas possibilitaram a aquisição de dados mais detalhados sobre as características de cada fonte estacionária inventariada, tais como a localização (coordenadas geográficas), utilizando um Sistema de Posicionamento Global (GPS), altura e diâmetro de chaminés, dentre outras variáveis.

A quantificação das emissões de poluentes atmosféricos foi baseada em relatórios de medições de chaminé realizados periodicamente pelas empresas. Do total de 246 fontes estacionárias inventariadas, 179 eram provenientes das indústrias de siderurgia e elaboração de produtos siderúrgicos com redução de minérios, inclusive ferro-gusa; nove da indústria de fabricação de blocos de concreto e produtos cerâmicos; quatro da indústria de fabricação de materiais para limpeza e polimento; e uma da indústria de fiação e tecelagem. Além dessas, também foram contabilizadas as emissões de uma indústria de produção de cimento a ser instalada na região. Nesse caso, os dados de emissão foram obtidos no processo de licenciamento existente no órgão ambiental, sendo constatado que a indústria terá 53 fontes de emissão.

A distribuição percentual das fontes estacionárias inventariadas é mostrada na Figura 1 e a localização dessas fontes está esquematizada na Figura 2.

As principais vias de tráfego do município de Sete Lagoas foram incluídas no inventário de fontes móveis emissoras de material particulado em decorrência da grande significância desse tipo de fonte (Figura 2). Para tanto, foram levantados dados junto à Divisão de Geoprocessamento da Secretaria de Planejamento da Prefeitura Municipal e à Delegacia de Trânsito de Sete Lagoas. As informações do fluxo de veículos em cada trecho das vias selecionadas não estavam disponíveis. Nesse caso, foi realizada uma contagem in loco, durante os períodos de tráfego mais intenso (das 8 h00 às 9 h30 e das 17 h00 às 18h30), para determinação do fluxo, sendo contabilizado o número de veículos leves e pesados.

Também não existem dados disponíveis sobre os fatores médios de emissão de material particulado (MP) dos veículos que circulam no município de Sete Lagoas. Portanto, os fatores médios de emissão (Tabela 1) foram estimados a partir de informações existentes para os veículos em uso da região metropolitana de São Paulo (RMSP) no ano de 2006. Esses fatores de emissão são encontrados no Relatório Anual de Qualidade do Ar - ano 2006 da Companhia Ambiental do Estado de São Paulo (CETESB, 2007).

A estimativa da distribuição de veículos leves do ciclo Otto, do tipo flex-fuel (bicombustível), bem como daqueles movidos à gasolina e a álcool existentes em Sete Lagoas, foi elaborada com base em informações do Ministério da Agricultura, Pecuária e Abastecimento, MAPA (BRESSAN, 2007) sobre a evolução da frota de veículos por combustível no Brasil. Foram adotados como referência os percentuais obtidos no ano de 2005 (81,4\% dos veículos do ciclo Otto são movidos à gasolina, 12,8\% a álcool, e 5,8\% são do tipo bicombustível).

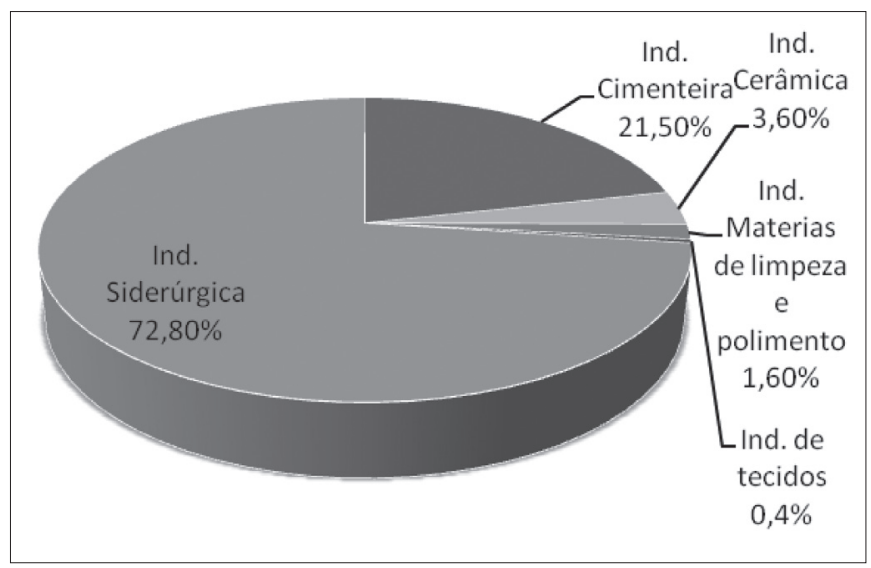

Figura 1 - Distribuição das fontes de emissão estacionária por tipologia industrial 


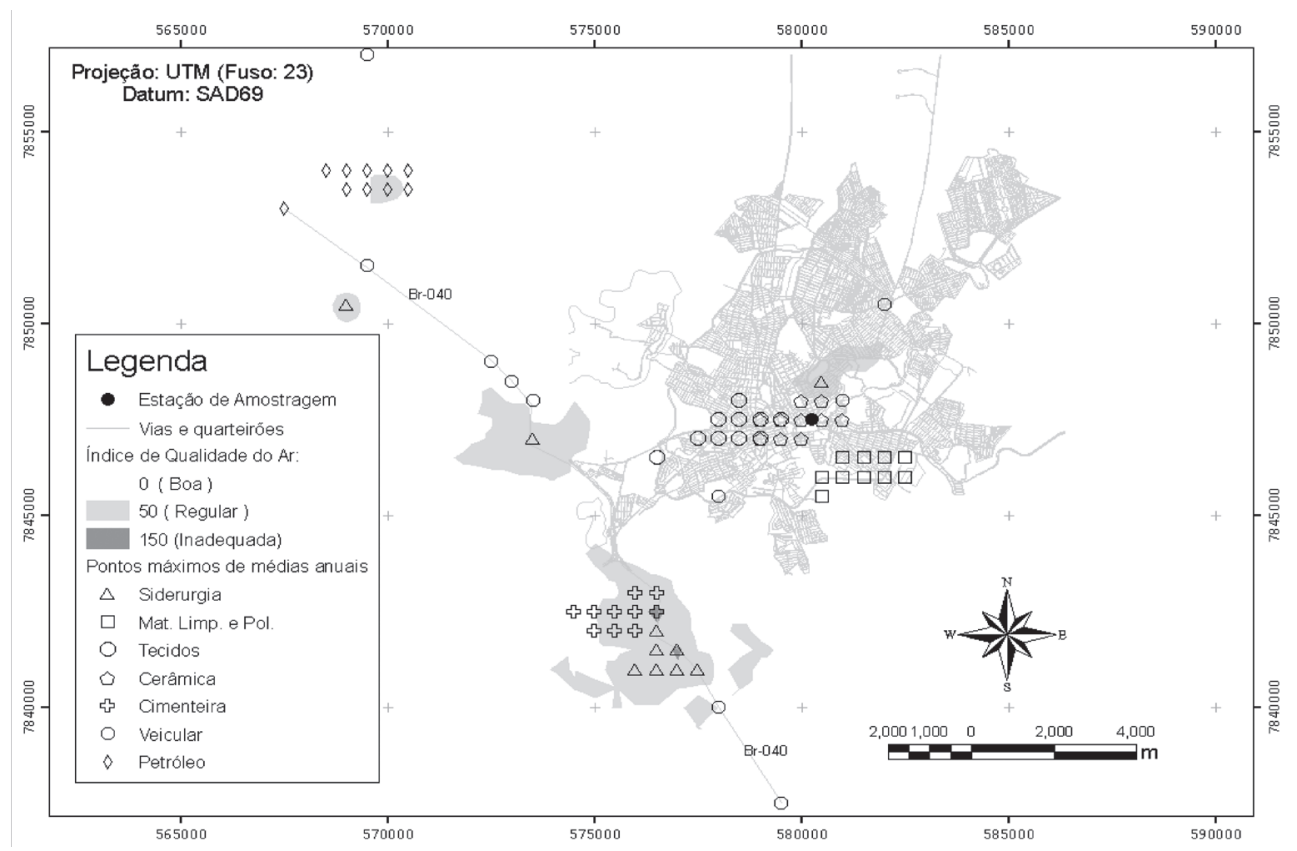

Figura 2 - Distribuição dos índices de qualidade do ar no município de Sete Lagoas

Tabela 1 - Fatores médios de emissão dos veículos

\begin{tabular}{llc} 
Fontes de emissão & Tipo de veículo & $\begin{array}{c}\text { Taxa de emissão de } \\
\text { material particulado } \\
(\mathrm{MP})^{3}(\mathbf{g} / \mathrm{km})\end{array}$ \\
\hline Tubo de escapamento & $\begin{array}{l}\text { Gasolina } C^{1} \\
\text { Álcool }\end{array}$ & 0,08 \\
& Flex (álcool) & - \\
& Diesel & - \\
Emissão do cárter e & Motocicleta e similares & 0,55 \\
evaporativa & Gasolina C & 0,05 \\
& Álcool & - \\
Pneus & Motocicleta e similares & - \\
\hline
\end{tabular}

1: Gasolina C - gasolina contendo $22 \%$ de álcool anidro e 450pMP de enxofre (massa); 2 : Diesel - com 350 pMP de enxofre (massa); 3: MP refere-se ao total de material particulado, sendo que as partículas inaláveis.são uma fração deste total.

Fonte: CETESB (2007).

Assumiu-se, ainda, que todos os veículos pesados (ônibus e caminhões) de Sete Lagoas são movidos a óleo diesel.

O fluxo de veículos nos trechos das vias selecionadas foi estimado a partir de contagens realizadas durante o mês de janeiro. Assim, a taxa de emissão de MP (expressa em g/s) de cada uma das vias de tráfego foi estimada levando-se em conta: os fatores médios de emissão veicular (vide Tabela 1), o volume de tráfego diário de veículos leves do ciclo Otto movidos a diesel, o percentual de veículos do ciclo Otto movidos a gasolina, bem como a distância percorrida por veículo, em cada uma das vias selecionadas.

Foi também considerado que todo o material particulado emitido pelas empresas possuía um diâmetro aerodinâmico menor que $10 \mu \mathrm{m}$, por ser essa a fração inalável que pode se acumular nas vias respiratórias e causar sérios problemas à saúde humana. Essa suposição se baseou também nos resultados de análises da granulometria do material particulado (QUEIROZ, 2006).

O estudo envolveu também a montagem de uma estação meteorológica para levantamento dos dados médios horários de direção e velocidade dos ventos, umidade relativa e temperatura do ar. Os sensores foram instalados a $10 \mathrm{~m}$ do solo em uma estrutura localizada em uma altitude privilegiada dentro da área de estudo, ao lado da estação de amostragem de ar indicada na Figura 2. Os parâmetros meteorológicos levantados foram: dados de direção e velocidade dos ventos, umidade relativa e temperatura do ar. Todas as informações obtidas foram processadas de forma a se obter dados horários correspondentes ao período de 23 de setembro de 2004 a 22 de outubro de 2005. Ao final, foi processado um total de 10.236 horas de dados.

As medidas dos parâmetros meteorológicos mostraram que velocidade média dos ventos no local de estudo foi igual a 1,39 m/s e a direção predominante dos ventos se deu de leste para oeste. Em relação à estabilidade, observam-se maiores percentuais para as classes A (32\%) e F (25\%), que evidencia uma predominância de comportamentos extremos de instabilidade (classe A) e estabilidade (classe F). A altura da camada limite variou de aproximadamente $2.000 \mathrm{~m}$ (outubro de 2005) a $60 \mathrm{~m}$ (julho de 2005), sendo que o seu valor médio foi de $763 \mathrm{~m}$.

\section{Modelo receptor}

O modelo receptor usado no presente estudo foi baseado no método de análise de fatores principais (AFP) (ORSINI et al, 1986). Um dos 
critérios adotados para construir o modelo de AFP é a escolha do método para estimar as matrizes relativas às variâncias das variáveis padronizadas e às variâncias dos erros aleatórios. A AFP foi adotada devido ao fato de não exigir informações ou suposições sobre a distribuição de probabilidades das variáveis padronizadas (HOPKE, 2003).

Os perfis das fontes emissoras foram determinados com base não apenas nos resultados das análises da composição elementar de amostras de solo e de resíduos sólidos, mas também com informações da literatura. Evidentemente, para algumas fontes essa comparação foi bastante difícil, já que foi feita com base em informações obtidas em outros países, onde as emissões são diferentes em função dos processos industriais e matérias-primas diversos dos encontrados no estado de Minas Gerais.

\section{Amostragem do material particulado}

A partir dos resultados da simulação numérica da dispersão de material particulado na atmosfera, aplicando o modelo ISC-3, foram identificadas as áreas onde ocorreram os maiores valores de concentração de material particulado (máximas em 24 horas) na área de estudo. Com base nesses dados, foi selecionado o ponto amostral com maior influência de fontes emissoras provenientes de tipologias industriais distintas. Esse ponto está posicionado na área central do município (Figura 2).

De forma a identificar a contribuição das principais fontes emissoras de material particulado, na área central do município de Sete Lagoas, foi realizada uma campanha de amostragem durante o período de 11 de janeiro a 14 de fevereiro de 2005. A concentração diária de material particulado inalável $\left(\mathrm{MP}_{10}\right)$ foi obtida por meio da análise de amostras coletadas em um amostrador de grande volume com cabeça de separação por impactação inercial, conhecido como $\mathrm{MP}_{10}$, fabricado pela Energética, Rio de Janeiro (RJ), Brasil.

\section{Amostragem de resíduos sólidos e solo}

Durante o período de amostragem do material particulado presente nos aerossóis atmosféricos, também foram coletadas amostras para a determinação da composição química dos resíduos sólidos gerados por diferentes indústrias e mineradoras da região de Sete Lagoas. A coleta foi realizada nas instalações de empresas da região: de produção de ferro-gusa a carvão vegetal, de fabricação de blocos de concreto, de fabricação de cerâmica e em mineradoras de calcário. Além disso, foram coletadas amostras da poeira retida no piso e nas vias de acesso localizadas nas proximidades da estação de amostragem de ar selecionada.

A amostragem de resíduos sólidos oriundos dos processos industriais foi obtida em pontos e profundidades diferentes. As parcelas foram misturadas de forma a se obter uma amostra homogênea que reunisse as características e propriedades da massa total da pilha original de resíduos. As poeiras coletadas dos pisos também foram obtidas de parcelas individuais que foram homogeneizadas, resultando em uma amostra composta a ser analisada. Uma vez no laboratório, as amostras passaram por quarteamento até a obtenção da massa desejada para cada técnica analítica a ser utilizada.

Para caracterização do solo da região de Sete Lagoas, foram obtidas amostras junto à Empresa Brasileira de Pesquisa Agropecuária (Embrapa). A unidade de pesquisa Milho e Sorgo da Embrapa de Sete Lagoas está situada em uma área cujo tipo de solo é predominante no município, o que determinou a realização de amostragem do solo nesse local. Além disso, o solo padrão da região se encontra devidamente caracterizado por essa instituição, o que propiciou a comparação dos resultados analíticos finais do solo coletado.

A amostragem de solo foi realizada em apenas um ponto, sendo coletadas amostras simples em três profundidades distintas, a saber: 15, 30 e $45 \mathrm{~cm}$. Esse ponto foi determinado por um técnico da Embrapa, em área com cobertura vegetal nativa e distante das intervenções antrópicas.

As informações das fontes citadas acima foram agrupadas por tipologia e descritas como (QUEIROZ, 2006):

- Fonte A: solos das proximidades da estação de amostragem de ar e solo padrão da região em estudo de acordo com caracterização feita pela Embrapa (latossolo vermelho escuro);

- Fonte B: extração e/ou beneficiamento de calcário: calcário moído, calcário misturado com solo residual e finos de calcário;

- Fonte C: fabricação de blocos de concreto e de produtos cerâmicos: areia, pó de brita e cimento, argila, resíduo de coque, e resíduos do forno;

- Fonte D: produção de ferro-gusa a carvão vegetal: pó de balão, finos de minério de ferro, finos de escória e poeira sobre os pisos externos da empresa.

\section{Metodologia analítica}

A gravimetria foi a metodologia usada para determinar a concentração média do material particulado coletado nos filtros usados para amostragem. Para tanto, a massa do filtro foi medida antes e após a amostragem; assume-se que a diferença entre elas corresponde ao material depositado durante o período de coleta. Calculada a massa e sabendo-se o volume de ar amostrado, registrado no totalizador do amostrador, foi possível determinar a concentração média do material particulado coletado. Para a pesagem dos filtros, foi utilizada uma balança digital de precisão de 0,1 mg, da marca Automarte, série AS5500.

As análises da composição mineralógica das diferentes amostras de interesse (solo, resíduos sólidos e material particulado) foram feitas pela técnica de difratometria de raios $\mathrm{X}$, método do pó, empregando-se um difratômetro de raios $\mathrm{X}$ de fabricação Rigaku, modelo 
Geigerflex, semiautomático, com monocromador de cristal curvo de grafite e tubo de raios $\mathrm{X}$ de cobre e uma interface informatizada para obtenção de dados digitais. A identificação de fases cristalinas/minerais foi obtida por comparação do difratograma de raios $\mathrm{X}$ das amostras com o banco de dados do International Center for Diffraction Data (ICDD) (JCPDS, 2003).

As amostras coletadas em filtro de microssílica foram recortadas em dimensões de $3 \times 3 \mathrm{~cm}$ e anexadas ao porta-amostra, procedendo a seguir à obtenção do difratograma de raios $\mathrm{X}$.

As amostras de resíduos sólidos e de solo foram homogeneizadas, quarteadas e distribuídas sobre uma superfície de vidro colante, formando uma camada de resíduos com diâmetro aproximado de 20 $\mathrm{mm}$. As análises levaram em consideração a intensidade das principais reflexões das fases e as comparações entre as mesmas, avaliandose assim as quantidades relativas de seus teores.

A determinação da composição elementar do material particulado, das amostras de solo e dos resíduos sólidos coletados foi feita pela técnica de análise por ativação neutrônica, mais especificamente, pelo método $\mathrm{k}_{0}$ (AAN-k ) (MENEZES et al, 2003). Para tanto, cada uma das amostras, após pesagem, foi acondicionada em tubos de polietileno adequados para a análise e depois irradiada na mesa giratória do reator TRIGA MARK-I IPR-R1, localizado no Centro de Desenvolvimento da Tecnologia Nuclear (CDTN/CNEN), cujo fluxo de nêutrons térmicos é de $6,6 \times 10^{11}$ nêutrons $\mathrm{cm}^{-2} \mathrm{~s}^{-1}$, com $100 \mathrm{~kW}$ de potência.

Durante todo o período de irradiação, as amostras foram acompanhadas de comparadores de sódio $(\mathrm{Na})$ em triplicata e de amostras de materiais de referência em duplicata, de forma a permitir a verificação da exatidão da técnica e garantir a reprodutibilidade das análises. Após um tempo de espera adequado para o decaimento dos radionuclídeos interferentes, foi executada a espectrometria gama em um sistema de detecção composto de um detector HPGe, Canberra (modelo GC1518, resolução de 1,85 keV para a energia de $1332 \mathrm{keV}$ do ${ }^{60} \mathrm{Co}$ ), conectado à eletrônica específica e programa de aquisição de espectros Maestro, Ortec. Deve ser ressaltado que elementos químicos tais como o Ni, Si, $\mathrm{Pb}$ e o $\mathrm{Cd}$ não podem ser determinados

Tabela 2 - Composição mineralógica das amostras de resíduos e solo

\begin{tabular}{|c|c|c|c|}
\hline \multirow{2}{*}{ Amostra } & \multicolumn{3}{|c|}{ Mineral identificado } \\
\hline & $>30 \%$ & 30 a $10 \%$ & $<10 \%$ \\
\hline Fonte A & Quartzo & $\begin{array}{l}\text { Calcita, caulinita, } \\
\text { microclina }\end{array}$ & $\begin{array}{c}\text { Gibsita, goethita, } \\
\text { hematita }\end{array}$ \\
\hline Fonte B & Calcita & Quartzo & $\begin{array}{l}\text { Caulinita, dolomita, } \\
\text { moscovita }\end{array}$ \\
\hline Fonte C & Quartzo & $\begin{array}{c}\text { Calcita, caulinita, } \\
\text { goethita, hematita, } \\
\text { magnetita }\end{array}$ & $\begin{array}{c}\text { Albita, larnita, } \\
\text { microclina, } \\
\text { merwinita, } \\
\text { moscovita, } \\
\text { periclásio, } \\
\text { portlandita }\end{array}$ \\
\hline Fonte D & Hematita & Quartzo & $\begin{array}{l}\text { Calcita, gibsita, } \\
\text { goethita, rutilo }\end{array}$ \\
\hline $\begin{array}{l}\text { Particulado } \\
\text { inalável }\left(\mathrm{MP}_{10}\right)\end{array}$ & Calcita & Quartzo & $\begin{array}{l}\text { Hematita, moscovita, } \\
\text { gibsita }\end{array}$ \\
\hline
\end{tabular}

pela $A A N-k_{0}$ por possuírem baixa secção de choque para nêutrons térmicos (MENEZES et al, 2003).

\section{Resultados e discussões}

Os resultados da distribuição dos índices de qualidade do ar (IQA) em Sete Lagoas, obtidos a partir da simulação numérica com o modelo ISC3, são mostrados na Figura 2. O valor desse índice é relacionado com a concentração medida do poluente (CETESB, 2008). Observa-se que, para o período considerado, em algumas regiões próximas das fontes emissoras, o IQA se encontra nas faixas regular e inadequada. Nas demais regiões, o IQA se encontra na faixa boa.

Na Figura 2, é também apresentada a localização dos pontos de máxima concentração anual de material particulado inalável, relativos a cada uma das tipologias industriais existentes na região. Como pode ser verificado, as regiões mais afetadas são aquelas localizadas ao longo da rodovia BR-040, onde estão posicionadas várias indústrias de produção de ferro-gusa, assim como na área central do município, onde a influência das emissões associadas à fabricação de materiais de limpeza e polimento, de fiação e tecelagem e de produtos cerâmicos é predominante. Vale ressaltar que a população fixa situada nas circunvizinhanças das indústrias localizadas ao longo da BR-040 é muito pequena, sendo essa uma área industrial.

Os resultados das medidas realizadas durante o período de amostragem (11 de janeiro a 13 de fevereiro de 2005) indicaram que os níveis de concentração de material particulado inalável $\left(\mathrm{MP}_{10}\right)$ na área de interesse foram elevados. Os dados de concentração de massa para $\mathrm{MP}_{10}$ indicaram que a qualidade do ar foi considerada regular em 53\% dos dias de amostragem. A concentração máxima observada durante o período foi de $132 \mu \mathrm{g} \mathrm{m} \mathrm{m}^{-3}$, a mínima de $16 \mu \mathrm{g} \mathrm{m} \mathrm{m}^{-3}$ e a média de $56 \mu \mathrm{g} \mathrm{m} \mathrm{m}^{-3}$.

Na Tabela 2, são apresentados os resultados das análises de difração de raios X para determinação da composição mineralógica das amostras de solo, resíduos sólidos e do material particulado presente no aerossol atmosférico do município de Sete Lagoas (MG). Esses dados foram sintetizados e apresentados de acordo com a presença dos minerais na amostra analisada.

A distribuição de frequências dos minerais mostrou a presença marcante de alguns silicatos, carbonatos e óxidos de ferro no material analisado. A calcita e o quartzo são predominantes nas amostras de fontes dos tipos A, B e C, estando presentes na fração maior que 30\%. Nessas amostras, os óxidos de ferro estão presentes nas frações menores que $30 \%$. Suas formas são variadas, podendo-se destacar a hematita, a magnetita e a goethita, que se apresentam mais frequentes na fração de 3 a $10 \%$. Nas amostras de fontes do tipo D, a hematita predomina.

Em relação ao material particulado inalável presente nos aerossóis da atmosfera de Sete Lagoas, a calcita está presente em uma frequência maior que 30\%. O quartzo é predominante na categoria de 30 a 10\%. Esses dados ressaltam que o processo de ressuspensão das 
Tabela 3 - Análise de estatística descritiva das AAN- $\mathrm{k}_{0}$ do $\mathrm{MP}_{10}$

\begin{tabular}{|c|c|c|c|c|c|c|}
\hline \multirow{2}{*}{ Elemento químico } & \multicolumn{5}{|c|}{ Concentração $\left(\mu \mathrm{g} / \mathrm{m}^{3}\right)$} & \multirow{2}{*}{$\begin{array}{l}\text { Número de amostras em que o } \\
\text { elemento químico foi detectado* }\end{array}$} \\
\hline & Média & Mediana & Desvio padrão & Mínimo & Máximo & \\
\hline $\mathrm{Al}$ & 0,09 & 0,09 & 0,04 & 0,005 & 0,18 & 30 \\
\hline As & 0,002 & 0,001 & 0,002 & 0,001 & 0,006 & 17 \\
\hline $\mathrm{Ba}$ & 1 & 0,8 & 0,9 & 0,12 & 6,1 & 28 \\
\hline $\mathrm{Br}$ & 0,006 & 0,005 & 0,005 & 0,001 & 0,02 & 20 \\
\hline $\mathrm{Cr}$ & 0,01 & 0,01 & 0,01 & 0,0009 & 0,08 & 30 \\
\hline $\mathrm{Cu}$ & 0,67 & 4 & 1,7 & 0,43 & 5,5 & 6 \\
\hline Dy & 0,0015 & 0,001 & 0,0007 & 0,0003 & 0,003 & 30 \\
\hline $\mathrm{Fe}$ & 5,2 & 4,7 & 3,2 & 0,003 & 15,4 & 30 \\
\hline $\mathrm{Ga}$ & 0,23 & 0,19 & 0,2 & 0,07 & 0,9 & 30 \\
\hline $\mathrm{Mg}$ & 0,04 & 0,04 & 0,02 & 0,008 & 0,10114 & 30 \\
\hline $\mathrm{Mn}$ & 0,09 & 0,07 & 0,07 & 0,02 & 0,3 & 30 \\
\hline $\mathrm{Na}$ & 14,3 & 9,7 & 13,6 & 2,9 & 57,1 & 30 \\
\hline $\mathrm{Sb}$ & 0,004 & 0,003 & 0,004 & 0,0003 & 0,02 & 30 \\
\hline $\mathrm{Sc}$ & 0,0007 & 0,0007 & 0,0004 & 0,00001 & 0,002 & 30 \\
\hline $\mathrm{Sm}$ & 0,5 & 0,02 & 2,4 & 0,001 & 12,1 & 25 \\
\hline Th & 0,002 & 0,002 & 0,002 & 0,0004 & 0,01 & 26 \\
\hline $\mathrm{V}$ & 0,00009 & 0,0001 & 0,0001 & 0,00001 & 0,0002 & 30 \\
\hline $\mathrm{Zn}$ & 0,11 & 0,09 & 0,07 & 0,02 & 0,31 & 30 \\
\hline
\end{tabular}

"Número total de amostras analisadas: 30 .

Tabela 4 - Principais concentrações elementares das amostras de solo e resíduos sólidos

\begin{tabular}{|c|c|c|c|c|}
\hline \multirow[b]{2}{*}{ Elementos químicos } & \multicolumn{4}{|c|}{ Concentração $\left(\mathrm{mg} \mathrm{g}^{-1}\right)$} \\
\hline & Solo & $\begin{array}{c}\text { Extração e beneficiamento } \\
\text { de calcário }\end{array}$ & $\begin{array}{l}\text { Fabricação de blocos } \\
\text { de concreto e produtos } \\
\text { cerâmicos }\end{array}$ & Ferro-gusa \\
\hline As & 0,07 & 0,002 & 0,02 & 0,02 \\
\hline $\mathrm{Al}$ & 217 & 31,8 & 123 & 50,6 \\
\hline $\mathrm{Ba}$ & 2,2 & 0,54 & 1 & 1,5 \\
\hline $\mathrm{Ca}$ & 75,5 & 283 & 399 & 150 \\
\hline $\mathrm{Cr}$ & 0,35 & 0,02 & 0,1 & 0,08 \\
\hline $\mathrm{Fe}$ & 126 & 13,6 & 282 & 534 \\
\hline $\mathrm{Ga}$ & 0,06 & 0,02 & 0,02 & 0,02 \\
\hline K & 12,3 & 31,6 & 76 & 1,2 \\
\hline $\mathrm{Mg}$ & 16,4 & 16,8 & 28 & 0,01 \\
\hline $\mathrm{Mn}$ & 0,97 & 0,31 & 20 & 4,4 \\
\hline $\mathrm{Na}$ & 1,2 & 4,5 & 8,3 & 0,97 \\
\hline $\mathrm{Nd}$ & 0,07 & 0,02 & 0,04 & 0,05 \\
\hline $\mathrm{Sr}$ & 0,38 & 0,37 & 2,6 & 1,07 \\
\hline Th & 0,03 & 0,009 & 0,02 & 0,01 \\
\hline $\mathrm{Ti}$ & 11 & 1,2 & 4,7 & 0,8 \\
\hline $\mathrm{Zn}$ & 1,3 & 0,04 & 6 & 0,08 \\
\hline
\end{tabular}

partículas de solo é um dos principais responsáveis pela emissão de material particulado na área de estudo.

Os resultados das concentrações dos elementos químicos existentes nas amostras do material particulado inalável $\left(\mathrm{MP}_{10}\right)$ são apresentados na Tabela 3. Como pode ser verificado, os elementos analisados que aparecem em maior abundância são o $\mathrm{Na}$, Fe e o Ba. Os perfis ou assinaturas das fontes A, B, C e D, obtidos por meio da análise por ativação neutrônica, podem ser visualizados na Tabela 4. Observa-se que, de uma maneira geral, os elementos químicos predominantes são $\mathrm{Al}$, Ca e Fe. 


\section{Análise de fatores principais aplicados ao material particulado inalável $\left(\mathrm{MP}_{10}\right)$}

Conforme mencionado anteriormente, o método de análise de fatores principais (AFP) foi o método selecionado para identificação das principias fontes emissoras de $\mathrm{MP}_{10}$ na área de estudo. A AFP é um modelo matemático chamado de modelo receptor, que tem como objetivo interpretar a estrutura interna da matriz variância covariância de um banco de dados multivariados (ORSINI et al, 1986), extraindo autovalores e autovetores da matriz de correlação dos dados. Ela trabalha com a variabilidade das concentrações elementares no tempo, reduzindo assim, a dimensão das variáveis necessárias para explicar a variância das concentrações medidas.

A AFP do material particulado amostrado foi realizada com 15 variáveis (concentrações de Al, Ba, Cr, Dy, Fe, Ga, Mg, Mn, Na, Sb, Sc, Sm, Th, V, Zn), já que foram considerados apenas os elementos químicos que foram detectados em pelo menos $75 \%$ das amostras analisadas (BRUNO, 2005). Portanto, aqueles elementos que, embora apareçam em altas concentrações não foram detectados em pelo menos $75 \%$ das amostras, não foram incluídos.

A escolha do número de fatores retidos foi feita com base na fração de explicação da variância total, na variabilidade das variáveis individuais e nos autovalores > 1 (HOPKE, 2003; ORSINI et al, 1986). Diante dos resultados, o modelo adotado foi aquele com cinco fatores e que apresentaram autovalores maiores que 1 .

$\mathrm{Na}$ Tabela 5 são também apresentados os resultados da aplicação da análise de componentes principais após rotação Varimax. A rotação foi realizada para proporcionar uma melhor clareza nas cargas fatoriais, possibilitando a identificação do fator com uma fonte poluidora conhecida (HOPKE, 2003). O peso associado a cada variável componente de um fator está relacionado com a correlação entre o elemento e o fator retido. Os valores negativos não são representativos nesta análise, pois seus valores absolutos não são próximos de 1 .

O Fator 1 explica 26,3\% da variabilidade dos dados e apresenta altos loadings para o Sc, Th, Fe, Ba e Zn, elementos que podem ser associados à ressuspensão do solo e de poeira de asfalto (LANDSBERGER; CREATCHMAN, 1999).

O Fator 2, cujo peso sobre a variância dos dados foi de 18,1\%, apresentou altos loadings para o $\mathrm{Al}$ e o V. O primeiro elemento pode estar associado à ressuspensão da poeira de solo. O segundo pode ser associado a processos industriais com queima de óleo pesado (ANDRADE et al, 1993). Portanto, esse fator pode estar relacionado às emissões das indústrias de fabricação de materiais para limpeza e polimento e de fiação e tecelagem, as quais utilizam caldeiras a óleo.

O Fator 3 explicou 11,8\% da variabilidade dos dados e apresentou altos loadings para o $\mathrm{Ga}$ e o $\mathrm{Na}$, que são elementos que podem estar associados a processo industriais (HO et al, 2003). Observando os dados da Tabela 4, pode-se atribuir a presença do $\mathrm{Na}$ às emissões da fabricação de blocos de concreto e produtos cerâmicos. O Ga, por sua vez, não é um elemento muito utilizado nos estudos de aplicação de modelos receptores. Além disso, as fontes conhecidas de emissão de Ga são muito poucas. Entretanto, o Ga pode estar presente em quantidades traço na bauxita (PEKNEY et al, 2006). Esse mineral, muitas vezes, pode ser incorporado à matriz de cimento Portland, material utilizado na fabricação de concreto (CASTRO; PANDOLFELLI, 2009).

Tabela 5. Pesos dos fatores com rotação VARIMAX e comunalidades referentes à composição elementar o $\mathrm{MP}_{10}$.

\begin{tabular}{|c|c|c|c|c|c|c|}
\hline \multirow{2}{*}{ Elementos } & \multicolumn{5}{|c|}{ Fatores } & \multirow{2}{*}{ Comunalidade (h2) } \\
\hline & 1 & 2 & 3 & 4 & 5 & \\
\hline $\mathrm{Al}$ & $-0,121$ & 0,894 & 0,118 & $-0,083$ & $-0,083$ & 0,86 \\
\hline $\mathrm{Ba}$ & 0,827 & $-0,126$ & 0,044 & 0,387 & 0,169 & 0,88 \\
\hline $\mathrm{Cr}$ & 0,211 & $-0,072$ & $-0,060$ & 0,735 & 0,199 & 0,68 \\
\hline Dy & $-0,015$ & 0,061 & 0,168 & 0,828 & $-0,271$ & 0,80 \\
\hline $\mathrm{Fe}$ & 0,881 & $-0,087$ & 0,119 & $-0,014$ & $-0,076$ & 0,81 \\
\hline $\mathrm{Ga}$ & $-0,016$ & $-0,194$ & 0,898 & 0,116 & 0,002 & 0,87 \\
\hline $\mathrm{Mg}$ & 0,037 & $-0,017$ & 0,068 & $-0,070$ & 0,079 & 0,91 \\
\hline $\mathrm{Mn}$ & $-0,199$ & 0,132 & 0,268 & 0,036 & $-0,832$ & 0,82 \\
\hline $\mathrm{Na}$ & 0,148 & 0,361 & 0,740 & $-0,058$ & $-0,194$ & 0,92 \\
\hline $\mathrm{Sb}$ & 0,333 & 0,065 & $-0,236$ & 0,015 & $-0,725$ & 0,71 \\
\hline Sc & 0,919 & $-0,008$ & $-0,104$ & 0,033 & $-0,188$ & 0,89 \\
\hline Sm & 0,083 & 0,495 & 0,517 & 0,046 & 0,147 & 0,73 \\
\hline Th & 0,901 & 0,008 & $-0,133$ & 0,227 & 0,089 & 0,90 \\
\hline V & $-0,054$ & 0,827 & $-0,121$ & $-0,140$ & $-0,123$ & 0,75 \\
\hline $\mathrm{Zn}$ & 0,652 & $-0,013$ & 0,183 & $-0,192$ & 0,004 & 0,53 \\
\hline Autovalores & 4,0 & 2,7 & 1,8 & 1,6 & 1,3 & \\
\hline $\begin{array}{l}\text { Variância } \\
\text { Explicada (\%) }\end{array}$ & 26,3 & 18,1 & 11,8 & 10,2 & 8,4 & \\
\hline $\begin{array}{l}\text { Variância } \\
\text { Acumulada (\%) }\end{array}$ & 26,3 & 44,4 & 56,2 & 66,7 & 75,1 & \\
\hline
\end{tabular}


O Fator 4 explica somente 10,2\% da variabilidade dos dados e possui altos loadings para o Dy e o $\mathrm{Cr}$, os quais podem ser associados a emissões de poeira de asfalto ou a processos industriais ( $\mathrm{HO}$ et al, 2003). O Fator 5 tem baixos loadings para diversos elementos com fontes prováveis distintas e explica a variabilidade de apenas 10\% dos dados, o que a princípio mostra que a AFP não conseguiu separar eficientemente todas as fontes poluidoras responsáveis pela massa de MP obtida.

Em geral, com exceção do Cr e do Zn, todos os elementos apresentaram alta comunalidade $\left(\mathrm{h}^{2}\right)$, igual ou acima de 0,71.

Os resultados obtidos por meio da aplicação da AFP corroboram aqueles obtidos nos estudos de dispersão atmosférica com o modelo ISC3, cujos resultados indicaram que os processos de fabricação de fiação e tecelagem, bem como de blocos de concreto e produtos cerâmicos, são os que mais contribuem para o aumento da concentração no local analisado na região central do município de Sete Lagoas. Uma vez que o ISC3 não considera a dispersão de fontes difusas, não foi possível estimar a concentração média anual associada às emissões de material particulado pelo processo de ressuspensão de poeira de solo e asfalto. Observando a Figura 2, pode-se ainda verificar que o ponto de amostragem de $\mathrm{MP}_{10}$ se encontra posicionado na direção predominante dos ventos (que se dá de leste para oeste), mais especificamente, na jusante do local onde as empresas de fabricação de fiação e tecelagem, bem como de blocos de concreto e produtos cerâmicos se encontram. Portanto, é de se esperar que a contribuição das fontes seja significativa nesse local.

\section{Conclusões}

O inventário das fontes de emissão de material particulado realizado em Sete Lagoas (MG) revelou que, nesse município, os principais agentes que contribuem para a poluição atmosférica são: a indústria siderúrgica, a indústria de material de limpeza e polimento, a indústria cimenteira, a indústria de tecidos, a indústria de cerâmica e a poluição veicular.

O estudo da dispersão atmosférica de poluentes, aplicando-se o modelo ISC3, permitiu a identificação das localizações com maior concentração de material particulado inalável $\left(\mathrm{MP}_{10}\right)$ na atmosfera, considerando-se a emissão simultânea de todas as fontes.

A análise da composição mineralógica das amostras de solo, resíduos sólidos e do material particulado presente nos aerossóis indicou a presença marcante dos silicatos, carbonatos e óxidos de ferro nos materiais analisados. A calcita foi o mineral predominante no material particulado inalável coletado, estando presente na fração maior que 30\%. Vale lembrar que o município de Sete Lagoas está localizado numa região cárstica, cuja principal característica é a solubilidade das rochas, em geral calcárias.

A análise da concentração elementar das amostras de solo e de resíduos sólidos mostrou que os elementos químicos presentes em maior abundância são $\mathrm{Al}, \mathrm{Ba}, \mathrm{Ca}, \mathrm{Fe}, \mathrm{K}, \mathrm{Mg}, \mathrm{Na}$, Ti e Zn. No caso do material particulado inalável presente nos aerossóis, foi observado que os elementos químicos predominantes são $\mathrm{Na}, \mathrm{Fe}, \mathrm{Cl}$ e o Ba.

Com a utilização da AFP, pode-se verificar que, na região central do município de Sete Lagoas, existem três fontes poluidoras responsáveis pela concentração do $\mathrm{MP}_{10}$ coletado durante o período de amostragem considerado (11 de janeiro a 13 de fevereiro de 2005). Todavia, não se pode descartar totalmente a existência de uma quarta fonte poluidora no local de amostragem.

O fator predominante, com explicação de $26,3 \%$ da variabilidade, foi aquele associado à ressuspensão de poeiras de solo e asfalto. A seguir, com explicação de $18,1 \%$, tem-se o fator associado ao processo de queima de óleo residual decorrente, por exemplo, da utilização de caldeiras a óleo pela indústria de fabricação de fiação e tecelagem. O fator de 3 com explicação de $11,8 \%$ pode ser relacionado ao processo de fabricação de concreto e produtos cerâmicos. No total, os fatores mencionados explicam aproximadamente 56,2\% da variabilidade total.

Os resultados obtidos demonstram que, apesar Sete Lagoas ser um polo produtor de ferro-gusa a carvão vegetal, as emissões atmosféricas das empresas associadas a essa tipologia industrial não contribuíram, durante todo o período de amostragem considerado, para o aumento da concentração de material particulado na área central do município. A sua contribuição é predominante ao longo da BR-040.

\section{Agradecimentos}

Os autores gostariam de agradecer a Dra Maria Ângela Barros Menezes e ao tecnólogo Walter de Brito, ambos do CDTN/CNEN, pela realização das análises por ativação neutrônica e por difração de raio X, respectivamente. Também gostariam de agradecer à Mestre Paula Guimarães Moura Queiroz pela coleta e análise gravimétrica das amostras, e à Secretaria de Planejamento do município de Sete Lagoas pela ajuda na elaboração do inventário das fontes fixas e móveis.

\section{Referências}

ANDRADE M.F.; ORSINI C.; MAENHAUT W. Receptor modeling for inhalable atmospheric particles in São Paulo, Brazil. Nuclear Instruments and Methods in Physics Research, v. B75, n. 1-4, p. 308311,1993
COMPANHIA NACIONAL DE ABASTECIMENTO (CONAB). O etanol como um novo combustível universal. 2008. [On-line] Disponível em: http://www.conab.gov.br/conabweb/download/nupin/etanol.pdf. Acesso em: 10 nov. 2009 
BRASIL. Ministério do Meio Ambiente. Conselho Nacional do Meio Ambiente, CONAMA. Resolução nº03 de 28 de junho de 1990. Dispõe sobre padrões de qualidade do ar, previstos no PRONAR. Brasília, DF, 1990.

BRUNO, R.L. Material particulado atmosférico na cidade de São CarlosSP: quantificação e identificação de fontes. Tese (Doutorado em Engenharia Química) - Departamento de Ciências Exatas e Tecnológicas da Universidade Federal de São Carlos, São Carlos, 2005.

CASTANHO, A.D.A.; ARTAXO, P. Wintertime and summertime São Paulo aerosol source apportionment study. Atmospheric Environment, v. 35, n. 29, p. 4889-4902, 2001.

CASTRO, A.L.; PANDOLFELLI, V.C. Revisão: conceitos de dispersão e empacotamento de partículas para a produção de concretos especiais aplicados na construção civil. Cerâmica, v. 55, n. 333, p. 18-32, 2009.

COMPANHIA DE TECNOLOGIA E SANEAMENTO AMBIENTAL (CETESB). Monitoramento da qualidade do ar no município de Araraquara/SP. Comparação entre os períodos de safra e entressafra de cana de açúcar. São Paulo: CETESB, 2000.

Modelo Receptor - Estudo de caracterização de aerossóis na região metropolitana de São Paulo - Cerqueira César. São Paulo: CETESB, 2002

Relatório de qualidade do ar no Estado de São Paulo 2007. São Paulo: CETESB, 2008.

GODISH, T. Air quality. 3rd ed. New York: Lewis Publishers, 1997.

$\mathrm{HO}$, K.F. et al. Characterization of chemical species in $\mathrm{PM}_{2,5}$ and $\mathrm{PM}_{10}$ aerosols in Hong Kong. Atmospheric Environment, v. 37, n. 1, p. 31-39, 2003.

HOPKE, P.K. Recent developments in receptor modeling. Journal of Chemometrics, v. 17, n. 5, p. 255-265, 2003.
JOINT COMMITTEE ON POWDER DIFFRACTION STANDARDS (JCPDS). Powder Diffraction File, International Center for Diffraction Data, Alphabetical Indexes, Sets 1-52, Pennsylvania: ICDD, 2003.

KERR, A.A.F.S.; ORSINI, C. Análise do particulado inalável em Cubatão/N. Parisi, São Paulo, Brasil. Anais da Academia Brasileira de Ciências, v. 68 n. 1, p. 181-191, 1996.

LANDSBERGER, S.; CREATCHMAN, M. Elemental analysis of airborne particles. Amsterdam: Gordon and Breach Science, 1999.

MENEZES, M.A.B.C. et al. $\mathrm{k}_{0}$-Instrumental Neutron Activation establishment at CDTN, Brazil: a successful story. Journal of Radioanalytical and Nuclear Chemistry, v. 257, n. 3, p. 627-632, 2003.

MIRANDA, R.M. et al. Characterization of aerosol particles in the São Paulo metropolitan area. Atmospheric Environment, v. 36, p. 345-352, 2002.

ORSINI, C. Characteristics of fine and coarse particles of natural and urban aerosols of Brazil, Atmospheric Environment, v. 20, n. 11, p. 22592264, 1986.

PEKNEY, N.J. et al. Application of PSCF and CPF to PMF-Modeled Sources of PM2.5 in Pittsburgh. Aerosol Science and Technology, v. 40, n. 10, p. $952-961,2006$.

QUEIROZ, P.G.M. Estudos da Poluição do Ar do Município de Sete Lagoas, MG Utilizando Técnicas Nucleares. Dissertação (Mestrado em Ciência e Tecnologia das Radiações, Minerais e Materiais) Centro de Desenvolvimento da Tecnologia Nuclear, Belo Horizonte, 2006.

UNITED STATES ENVIRONMENTAL PROTECTION AGENCY, USEPA. User's guide for the industrial source complex (ISC3) dispersion models, v. 1-2. EPA Publications, EPA-454/B-95-003a and EPA-454/B-95-003b. Research Triangle Park, NC: USEPA, 1995. 